\title{
“I will take my flip-flops, put them on and walk to church": Understanding quality of life of children with cerebral palsy in a rural setting
}

\author{
*Annika Savage. B Occ Ther (US), MOcc Ther (UKZN). \\ https://orcid.org/0000-0002-2508-8278 \\ Occupational therapist in clinical private practice, Iswepe, Mpumalanga, South Africa. Operational manager at LETCEE, Greytown, South \\ Africa.
}

\author{
Gina Rencken. B Occ Ther (UP), M Occ Ther (UFS). \\ https://orcid.org/0000-0002-3658-4453 \\ Lecturer Discipline of Occupational Therapy, College of Health Sciences, University of KwaZulu-Natal, South Africa.
}

\author{
Thavanesi Gurayah. B OccThe (UDW), M Occ Ther (UKZN). \\ https://orcid.org/0000-000 I-9005-6355 \\ Lecturer Discipline of Occupational Therapy, College of Health Sciences, University of KwaZulu-Natal, South Africa.
}

\section{* Masters student in the Discipline of Occupational Therapy, College of Health Sciences, University of KwaZulu-Natal, South Africa, at the time of the study.}

Introduction: Cerebral Palsy (CP) is a chronic, debilitating condition affecting most spheres of a person's life. This study aimed to explore the perceived factors impacting the quality of life (QOL) of a selected group of children with CP living in the rural Umzinyathi district of KZN, South Africa.

Methodology: The study had a qualitative, phenomenological design with purposeful sampling to recruit children with CP and their parents. Ten individual interviews were conducted, two with children with CP and eight with parent-proxies. One focus group was also conducted with the parent-proxies. Thematic analysis was used to interpret the data.

Findings: Three themes emerged from the data: Physical wellbeing, Activity participation, and Family and community. These themes encompassed the lived experiences of the children with CP, as well as the perceived factors that impacted on their QOL. Each theme was further broken down into subthemes, with a total of fourteen subthemes.

Conclusion: $Q O L$ in rural areas is a complex and multi-faceted construct. Understanding the factors that impacted the children's $Q O L$, will enable occupational therapists to offer client-centred meaningful interventions. When aiming to improve the QOL of children with CP in rural areas, awareness campaigns, anti-stigma messages and support for caregivers are vital.

Keywords: quality of life, cerebral palsy, rural occupational therapy, client centred intervention, caregiver support.

\section{INTRODUCTION}

Cerebral palsy (CP), a chronic and debilitating condition affecting movement and posture, is caused by an injury or defect to a developing brain'. CP remains the largest cause of disability in children across the world ${ }^{2}$, with suggested prevalence rates in South Africa (SA) ranging between $1 \%$ to $8 \%{ }^{3}$. Given the pervasive impact on people's lives, it is imperative to consider more than just the biomedical aspects of CP, to understand the dynamics that affect the whole person4. Quality of life (QOL) is defined as a multidimensional construct that is used to assess wellbeing across various domains of life $^{5}$, including physical, social, psychological and environmental components. However, the focus of occupational therapists remains on assessing and addressing individual dysfunctions and physical symptoms ${ }^{6}$, rather than understanding and challenging the constraints that the specific environment has on occupational opportunities.
Research shows that "activity participation of children with similar types and severity of CP varies according to where they live"7, highlighting the importance of identifying the indicators of QOL specific to the setting in which children live. Environmental factors can be as influential in children's activity participation as the type of CP they have $^{7}$. It is therefore necessary to assess the whole context to treat the child holistically and effectively. This study aimed at understanding the various factors that impacted the QOL of children with $C P$ in a rural South African setting.

\section{LITERATURE REVIEW}

Prevalence rates of CP in SA are much higher than the global prevalence rates of $0,2-0,3 \% \%^{2,3}$. This can be attributed to poor antenatal care, large numbers of children being born at home, dehydration, malnutrition and poor management of pre- and postnatal infections ${ }^{3}$. Developing countries not only have a much higher prevalence of 
$\mathrm{CP}$, but the presentation of the $\mathrm{CP}$ and the co-morbidities are also different ${ }^{8}$. A recent study in Botswana indicated that $41 \%$ of their children with CP fell into the most severe category of motor impairment (GMFCS V) 9 . The majority of children with CP accessing public health services in SA presented with multiple and complex impairments².

QOL is a relatively new field in health research ${ }^{10}$, and has mainly been studied in developed countries" ${ }^{\prime}$. Power et al. suggests the reason $\mathrm{QOL}$ is often overlooked in developing countries can be attributed to the complexities associated with its measurement ${ }^{5}$. QOL is a widely used outcome measure amongst practitioners in health and social sciences ${ }^{12}$, but while common in other fields, there remains limited application of QOL measures by occupational therapists $^{12}$. Hammell ${ }^{13}$ suggests that occupational therapists often state the enhancement of QOL as one of their primary goals, yet it is not supported by their outcome measures or literature, despite the links QOL has to occupational therapy philosophy'2. Both occupational therapy and QOL have a "multifaceted, holistic, and client-centred approach to people's lives" and specifically look at the roles and functions that offer meaning and value to clients ${ }^{12}$.

By understanding what impacts the $\mathrm{QOL}$ of children with $\mathrm{CP}$ in rural areas, occupational therapists will be better equipped to adopt a client-centred approach in practice. Rural occupational therapists will be able to offer assessment, intervention and outcome measures that are informed by the views of the people they treat ${ }^{13}$, adding real value to the lives of their patients.

\section{METHOD}

\section{Study design}

The study had a qualitative, phenomenological design ${ }^{14}$, investigating the participants' subjective perceptions of their QOL, as selfreported or through a parent-proxy.

\section{Research setting}

The study was conducted in the Umzinyathi district of KZN, SA, which is one of the most economically deprived areas in the country ${ }^{15,16}$. The majority of the population has a lower socioeconomic status, and their access to basic health and education services is poor $^{15,16}$.

\section{Ethical considerations}

Ethical clearance and gatekeeper permission was obtained from the Biomedical Research Ethics Council of University of KwaZulu-Natal (UKZN), UKZN: Reference BE059/16 and from the Department of Health, KwaZulu-Natal: Reference I I5/I6, KZ_20I5RP59_640. Permission was also obtained from the University of Melbourne, Australia, to use the data collection questions from Waters et al.'s study as the basis for tool development ${ }^{17}$.

Occupational therapists at each hospital in the district identified possible participants and disseminated invitations and consent forms to invite participation in the study. At a group meeting potential participants were given the opportunity to ask questions about the research, and the researcher explained the invitation package, which included participants' confidentiality and voluntary participation, pseudonym use to maintain participants' anonymity, the right to withdraw at any time, and the researcher's ethical responsibilities. All communication was offered in English and isiZulu.

\section{Tool development}

The list of eleven questions used by Waters et al. was modified to create an interview schedule. A pilot study was conducted in the Umvoti subdistrict of Umzinyathi to test the relevance and comprehensiveness of the new questions. Following changes to the questions, another pilot interview with a different participant was conducted to test the new questions. The final interview schedule was found to elicit the type of rich information required for data collection.

\section{Sampling}

Purposive sampling ensured maximum variation within the sample. Inclusion criteria were that the participants had to be diagnosed with CP, be between 6-12 years, reside within the Umzinyathi district and be able to communicate verbally or have a parent-proxy who spent a significant portion of the child's waking time with them. The number of participants recruited was based on the evidence of data saturation ${ }^{17}$. The sample size was ten, comprising two children and eight parent-proxies. Table I (p76) shows the demographics of participants.

\section{Data Collection}

The researcher conducted and audio-recorded ten semi-structured interviews, as well as one focus group for parent-proxies with the assistance of an isiZulu translator. Data collection was done at communal locations, such as local clinics, hospitals and community halls convenient for the participants. Participants were reimbursed for their travel costs and refreshments were provided.

\section{Data Analysis}

The recordings from the interviews and focus group were transcribed verbatim and then translated. The English translations of the isiZulu responses were used for data analysis. Thematic analysis was used to analyse the data using an inductive approach and following the six phases as set out by Braun and Clarke ${ }^{18}$. Familiarisation with the data was done through reading transcripts and listening to audio recordings. Initial codes were generated by highlighting important aspects in the transcripts before searching for themes. This was done independently by all three authors. Potential themes were then reviewed and finally three major themes with fourteen subthemes were defined.

\section{FINDINGS}

What follows now, is a combination of the children and the parentproxies' descriptions of the children's daily lives, and the factors that impacted the QOL of these children with CP. Three themes emerged from the data, namely Physical wellbeing, Activity participation, and Family and community. Figure I (p77) presents the themes and subthemes.

\section{Theme I: Physical wellbeing}

This theme described the children's physical abilities and health as they had an impact on the children's QOL. It is divided into three subthemes: Mobility and posture, Comorbidities, and Communication and pain, ensuring a complete understanding of the children's physical capabilities and health status.

\section{Mobility and posture}

Participants had varying physical abilities: "I put down pillows to support her so that she can sit" (Nompilo). Other children were sitting independently: "she is now able to sit." (Thuli), thereby increasing the activities they were able to participate in, and their interaction with others. Fezeka verbalised: "[Nolwazi's] life is better; she now 
Table I: Demographic information of participants.

\begin{tabular}{|c|c|c|c|c|c|c|c|c|c|c|}
\hline Pseudonym & Amahle & Nomzamo & Mvelo & Sizwe & Mbali & Thabiso & Ngcebo & Siyanda & Ntombi & Nolwazi \\
\hline Age & 8 & 6 & 6 & 7 & 10 & 10 & 12 & 9 & 9 & 11 \\
\hline Gender & Female & Female & Male & Male & Female & Male & Female & Male & Female & Female \\
\hline Type of CP & Ataxic & Athetoid & Ataxic & $\begin{array}{l}\text { Spastic } \\
\text { quadri- } \\
\text { plegia }\end{array}$ & $\begin{array}{l}\text { Spastic } \\
\text { hemi-plegia }\end{array}$ & $\begin{array}{l}\text { Spastic } \\
\text { quadri- } \\
\text { plegia }\end{array}$ & $\begin{array}{l}\text { Spastic } \\
\text { quadri- } \\
\text { plegia }\end{array}$ & $\begin{array}{l}\text { Spastic } \\
\text { quadri- } \\
\text { plegia }\end{array}$ & $\begin{array}{l}\text { Spastic } \\
\text { quadriplegia }\end{array}$ & Athetoid \\
\hline $\begin{array}{l}\text { GMFCS } \\
\text { Level }\end{array}$ & IV & $\mathrm{V}$ & II & $\mathrm{V}$ & V & $\mathrm{V}$ & $\mathrm{V}$ & V & IV & $\mathrm{V}$ \\
\hline CFCS & II & V & II & V & IV & V & V & IV & V & V \\
\hline $\begin{array}{l}\text { Type of } \\
\text { reporting }\end{array}$ & $\begin{array}{l}\text { Self- } \\
\text { report }\end{array}$ & $\begin{array}{l}\text { Parent- } \\
\text { proxy }\end{array}$ & $\begin{array}{l}\text { Self- } \\
\text { report }\end{array}$ & $\begin{array}{l}\text { Parent- } \\
\text { proxy }\end{array}$ & $\begin{array}{l}\text { Parent- } \\
\text { proxy }\end{array}$ & $\begin{array}{l}\text { Parent- } \\
\text { proxy }\end{array}$ & $\begin{array}{l}\text { Parent- } \\
\text { proxy }\end{array}$ & $\begin{array}{l}\text { Parent- } \\
\text { proxy }\end{array}$ & $\begin{array}{l}\text { Parent- } \\
\text { proxy }\end{array}$ & $\begin{array}{l}\text { Parent- } \\
\text { proxy }\end{array}$ \\
\hline $\begin{array}{l}\text { Home } \\
\text { language }\end{array}$ & isiZulu & isiZulu & isiZulu & isiZulu & isiZulu & isiZulu & isiZulu & isiZulu & isiZulu & isiZulu \\
\hline Religion & $\begin{array}{l}\text { Nazarene } \\
\text { (Shembe) }\end{array}$ & $\begin{array}{l}\text { Nazarene } \\
\text { (Shembe) }\end{array}$ & $\begin{array}{l}\text { Nazarene } \\
\text { (Shembe) }\end{array}$ & $\begin{array}{l}\text { Nazarene } \\
\text { (Shembe) }\end{array}$ & Catholic & Christian & Christian & Christian & $\begin{array}{l}\text { Nazarene } \\
\text { (Shembe) }\end{array}$ & Christian \\
\hline $\begin{array}{l}\text { Primary } \\
\text { caregiver }\end{array}$ & Nompilo & Thuli & Nomusa & Buhle & Nomfundo & Nelisiwe & Nkululeko & Zanele & Thabile & Fezeka \\
\hline $\begin{array}{l}\text { Relationship } \\
\text { to child }\end{array}$ & Mom & $\begin{array}{l}\text { Grand- } \\
\text { mother }\end{array}$ & Mom & $\begin{array}{l}\text { Grand- } \\
\text { mother }\end{array}$ & $\begin{array}{l}\text { Grand- } \\
\text { mother }\end{array}$ & Mom & Father & Mom & Mom & Mom \\
\hline
\end{tabular}

likes to sit. Her life is not the same as before."

Posture also affected participation in activities. Nkululeko explained: "[Ngcebo] is always lying on the bed. I pick her up and when I feel tired, I put her on her wheelchair [or] take her back to the bed". Ngcebo's physical size made it difficult for her to be lifted and moved. Buhle mentioned it was the same for Sizwe: "He spends most of his time here [lying on a mattress]. Sometimes I change his position."

Mbali lived with her grandmother and did not have a wheelchair. Nomfundo (grandmother) said "it is difficult [to attend community events] because I have to carry her on my back." Fezeka concurred: "The distance from the house to the tar road is long so I have difficulty carrying my child because it is very rocky. She also does not like going on my back anymore [...], so it would be easier if she has a wheelchair." Amahle (child) named walking by herself as something she would like to do. Being able to walk or move around was not only about the movement itself. Having mobility (with or without an aid) gave children the opportunity to participate in family life and community events. Nomfundo said "I hope that one day [Mbali] can have a wheelchair so that she can play with other kids".

\section{Comorbidities}

Comorbidities and secondary problems were also mentioned as impacting on the children's QOL: "He is epileptic" (Nelisiwe). Zanele said: "In summer, sometimes he gets diseases like pressure sores." These comorbidities affect QOL by either causing pain or limiting the children's participation in activities.

Vision and speech impairments were also cited. Some of the children were unable to see while others had limited eyesight. Zanele explained that "[Siyanda's] eyesight is not good" but he is able to notice changes in light: "when the doors are closed, he can tell and when they are open, he also knows".

\section{Communication and pain}

Adequate communication, whether verbal or non-verbal, gave children the opportunity to make choices for themselves. Nomfundo chose Mbali's clothes and activities based on her non-verbal communicated preferences: "She laughs if she is happy with it" and "when I give her the clothes that she likes, she shows by her face that she is happy with what I put on". Zanele verbalised "when [Siyanda] is well, he laughs a lot" and "when he is not well, he cries a lot".

The majority of the children communicated by crying when something was wrong. "When she is hungry or something is not right and she is not feeling well, she cries" (Nkululeko, parent). For most children, crying was the only way to communicate pain. This was often difficult for caregivers and meant that the cause of the pain was not easily established and addressed. "When my child is not well I get very hurt because she cannot say where she feels the pain" (Thabile). Fezeka shared this concern: "I never know where the problem is".

Other communication methods were also mentioned. Thabiso liked making sounds. "I know [he is well] when he wakes up in the morning and makes a noise. If he is not well he is quiet." Siyanda used his hands. "If you ask him 'are you okay?' he responds by putting his thumb up." It was not necessarily the communication methods that impacted the children's QOL, but rather the ability to be understood by their caregivers. In this regard responsive caregiving played as important role, together with the child's ability to communicate.

\section{Theme 2: Activity participation}

This theme described the activities rural children with CP participate in or are unable to participate in, as described by the children themselves and parent-proxies.

"They should be going to school, but they are not"

Mvelo, aged 6, attended a crèche despite being of school-going age. Nomusa (his mother) said none of the primary schools in his area were able to accommodate him. When asked if he would like to go to school, Mvelo said an affirmative "school" and smiled. He would like to start going to school "tomorrow".

Although Mvelo was included in the class of about 20 children at a local crèche, he said he preferred to play "alone". His mom added that in the past some of the other children had hit Mvelo to get toys from him. His teacher did not understand when he tried to report this, due to his laboured speech.

Amahle had never attended school or crèche but stated: "I would love to". Every morning she longs for schooling: "My sister leaves me and goes to school." Nompilo, her mom, tried to teach Amahle to read and write, but her own skills were limited, making it difficult. 
THEME 1:

Physical wellbeing

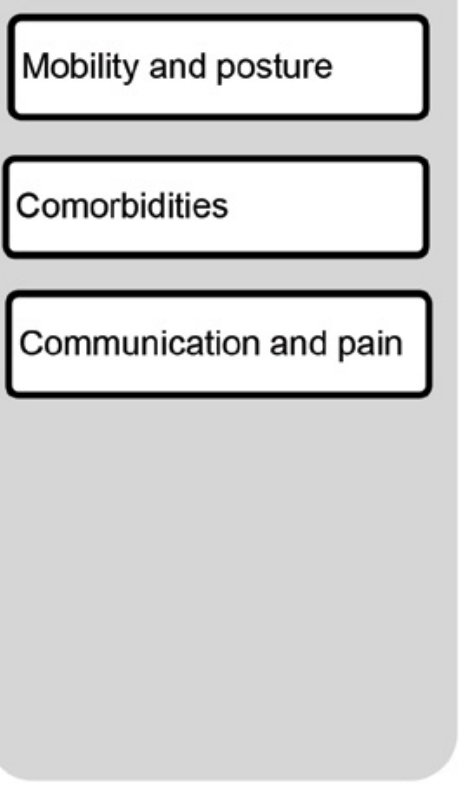

THEME 2:

Activity participation

'They should be going to school but they are not'

Need for assistance with daily activities

'He laughs a lot and plays nicely'

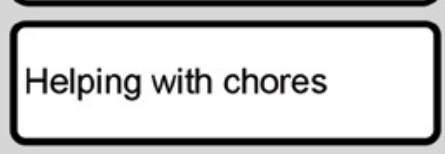

THEME 3:

Family and

community

Strong relationships between

children and caregivers

Attitudes towards children with $\mathrm{CP}$

'No one to help me'

Deriving meaning from church and religion

Financial difficulties

Access to services

Thinking about the future

Figure I: Schematic representation of themes.

However, when asked about her favourite activity, Amahle said "I like reading", which Nompilo clarified was paging through magazines and newspapers. Like Amahle, none of the other children in this study had ever been in a formal learning environment. Thuli said: "They should be going to school, but they are not. They cannot go because there are no special schools in the area."

Most of the parents had approached local mainstream schools, but they were unwilling or unable to accommodate the children with $\mathrm{CP}$ in these schools. Parents displayed their understanding, as evident in the quote: "no one there is competent in working with children with special needs and the teachers can't manage with normal kids at the same time". However, Zanele felt it was important for Siyanda to get the opportunity to learn: " $[\mathrm{He}]$ should be able to get to spend time with other children and learn as well".

There was only one public special school in the district; around two hours' drive away from all the participants' homes. Nelisiwe had applied there and "[Thabiso] is waiting for space". There was a high demand for space in this school, specifically in the hostel, as most children could not travel that distance daily. It was further compounded by the fact that Thabiso was ten years old with no educational history, making it difficult for him to integrate into a formal school environment.

Not all the parents were willing to send their children to school, because it would require their children to live away from home. "These schools are far and as parents we get worried" (Thuli, parent). "What I would like is for government to help us with schools for disabled children in our rural areas so that we are able to be closer to our children" (Nompilo, parent). The quality of staff at schools was also important. "I am willing for [Mbali] to attend a special school but I am afraid that people who are not trained will hit her. [Mbali] can't speak. She can't say anything if someone hits her" (Nomfundo).

Parents tried to make up for not attending school by doing learn- ing activities at home. "During the afternoon, I try to tell stories to [Mbali] but because of my poor vision I can't read properly." (Nomfundo).

One parent thought that her child should not attend school yet. "When she reaches a stage where she is better, she can start with education". This highlighted the fact that the parents did not necessarily understand the chronic nature of $\mathrm{CP}$.

\section{Need for assistance with daily activities}

Most of the children were dependent on their caregivers for selfcare activities. Cognitive and motor barriers prevented children from gaining independence. Zanele said she "tried to teach [Siyanda] to go to the toilet but he could not learn". Buhle said Sizwe "cannot go to the toilet and he cannot feed himself because he cannot move his arms".

When asked about Thabiso's feeding, Nelisiwe, his mom said: "He cannot hold [the spoon] on his own. He drops it". This was similar to the other children, and dressing was difficult for most of them. "I put his clothes on for him because he cannot dress himself." (Nomusa)

Nomfundo also had to bath Mbali or ask the older female cousins to bath her. Mbali "can't use her hands to wash herself but she grabs the towel with her left hand. She is strong then." (Nomfundo).

Amahle and Mvelo were more independent in their self-care activities. In the morning, they bathed and ate independently. They liked eating "maas, banana and mageu" and "eat porridge and Danone [yoghurt]" (Amahle, child).

\section{"He laughs a lot and plays nicely"}

Play was universally mentioned as contributing to a good QOL. Toys that made sounds and music were common. Nompilo said Amahle "loves [music]". Fezeka agreed: "[Nolwazi] also likes noise because when the radio is playing, I see that she plays with her foot wanting to dance".

Three of the parents mentioned that their children played 
with "toys that we borrow from the [toy library]". A local NPO ran a mobile toy library in these areas which gave the participants the opportunity to play with other children. Nomfundo said "there is no one [to play with] unless she is taken by the [toy library] to the playgroups where other kids are."

Amahle said she played with her sister and a friend in the afternoons. After crèche, Mvelo played alone at home until his siblings arrived from school. His favourite activity was the "swing".

For some children, their parent was their only playmate. "He can't go out to play with the others" (Zanele, parent). "He looks at the other children playing outside as though he would like to be there" (Buhle, parent). "It affects her badly seeing other children playing" (Thuli, parent).

Playing did not always require toys: "I [...] put her on my lap and play with her. She laughs. I play music on my phone and make her listen to it even though she will not say that she can hear" (Fezeka). For Sizwe, the best play was clapping his hands.

\section{Helping with chores}

Nompilo reported that "[Amahle] likes washing a lot" and she gave Amahle the smaller clothing items to wash, rinse and wring out. When asked if he enjoyed doing the washing, Mvelo gave an affirmative " $h m m$ " and added "soap". His mother explained that Mvelo liked to make soap bubbles to play with. Amahle further said "I know how to [cook]", with her mom explaining that Amahle helped with washing vegetables and stirring food. Nompilo mentioned that Amahle also helped with the livestock. "She follows the small goats when they go inside the house and chases them out."

Some children were unable to help around the house. Nkululeko said that Ngcebo did not participate in domestic life, but she went outside when her mother put her in the wheelchair because "she enjoys it when she sees the sun."

\section{Theme 3: Family and community}

This theme described the contextual factors that had an impact on the children's QOL. It is divided into seven subthemes, each describing one aspect of the context.

\section{Strong relationships between children and caregivers}

All of the caregivers in this study expressed their love and care for their children with CP. Comments like "I love my child" (Zanele) and "she is a God-given child" (Nomfundo) were common. However, the acceptance did not come immediately for all: "now I have accepted that my child is like this, but before it was very difficult" (Fezeka). Two of the grandmothers took on the role of primary caregiver due to abuse or neglect by the child's parents. "[Mbali]'s father was abusive towards [her]" (Nomfundo). "Her parents neglected her" (Thuli).

Interactions with family members were mentioned as one of the most important aspects of a "good life" (Buhle), and something the children enjoyed. Zanele said she talked to Siyanda, "and play with him and he gets happy and laughs". "What I have noticed is that [Nomzamo] gets really happy when I come back from fetching water because when I open the door, she starts laughing and becomes happy" (Thuli).

Strong bonds between children and caregivers were evident. Thuli (parent) mentioned "when [Nomzamo] does not see me, she looks around to see where I am. What makes her really happy is seeing me next to her". The attachment between them made it difficult for Nomfundo to leave Mbali with anyone else if she needed to do chores: "When I am not around, she cries non-stop until I arrive and calm her".

Siyanda "is very happy when he plays with his sister" (Zanele).
Amahle "has a good relationship with her siblings. That is what I like the most. She is happy when she sees them" (Nompilo, parent).

\section{Attitudes towards children with CP}

Attitudes towards children with CP had a direct impact on their acceptance, inclusion in activities and QOL. Although the attitudes of all family members were caring towards the children, there was a stark difference in the way different parents viewed the children and their abilities. Nkululeko said: "I feel sorry for [Ngcebo] because she cannot do anything." In contrast, when asked if there is anything Siyanda could not do because he had CP, Zanele said "no". She explained that Siyanda likes to play and "he gets happy when I teach him to walk". Both these children had spastic quadriplegia (GMFCS level V); however, their parents' expectations of what they were able to do were opposites.

Limited explanations by healthcare workers and misinformation with regards to the children's $\mathrm{CP}$ were common, and with stigma rife in the community, CP was often misunderstood. Thuli explained: "I do not even know what CP is... They didn't tell me what happened to cause the disability. The people at the clinic said that sometimes it is caused by lack of immunisation." This is something she did not understand, as Nomzamo received all her immunisations. Her current understanding of $\mathrm{CP}$ is outlined in the quote that follows:

"[Neighbours] were trying to attack me [spiritually], but because I am old and strong, maybe that thing attacked the child. Maybe they were jealous. The child was normal. We went to sleep [...] then [Nomzamo] didn't wake up. When I went to check up on her, she was disabled. I believe it was witchcraft."

In the wider community, some people did not have favourable views of children with disabilities. Thuli said that when people saw Nomzamo, "some run away". Other parents said that neighbours "don't bring their children" to come play at their house out of fear of the children with CP. "Even when you take a taxi with the child, and they touch the person sitting next to you, the person gives you funny looks." (Thabile, parent). Nompilo agreed: "we also get discriminated against in our communities".

Stigma and the views of others caused some parents to keep their children indoors most of the time, out of fear of victimisation. "We are discriminated against, but our children are the same as all the others" (Thabile). Fortunately, not all community members had the same view of children with disabilities. According to Zanele, "our communities love us" and it was only a few people who still viewed Siyanda negatively. Thuli and Nomfundo remained hesitant to let their children out of the yard. "She is always with me so nothing can harm her" (Nomfundo).

\section{"No one to help me"}

It was not just strangers who treated children with CP differently. Extended family also withdrew from the children because of the CP. "The nearby family have changed. The father used to visit before [Sizwe] got CP. Now he never even phones" (Buhle). However, when the extended families drew closer, it offered the caregivers a positive coping resource. "My family is treating the child and I well and they love us both. They encourage me" (Zanele). "The family understands and is very supportive" (Fezeka, parent).

Without practical support and acceptance from family and the community, parents were often overwhelmed by the role of caring for a child with complex disabilities. "You cannot do anything, including house chores such as fetching firewood and fetching water. If you ask someone to fetch water for you, they expect to be paid" (Nelisiwe, parent). Without physical assistance, caregivers were often "forced 
to leave the child alone in the house and go and wash clothes" (Zanele, parent). Highlighting the need for respite from caregiving, Nompilo said "it would be nice to have a day where we as mothers are taken to go and buy food in town".

\section{Deriving meaning from church and religion}

Attending church and having a strong belief in God was important for most participants. However, participants encountered significant challenges with attending church regularly. Thuli mentioned that "it takes about 2 hours" to walk to church, and it was difficult with Nomzamo on her back. She had to cross a river and walk up a hill, so she could not go every week. Nomfundo and Buhle felt the same: "We can't go to church". The caregivers and children seemed to derive immense joy and upliftment when they did attend church. Thabile said Ntombi "goes to church and when she is there, she laughs a lot and makes a lot of noise. When people sing, she starts laughing".

Mvelo went to church with his family every week. When asked if he enjoyed church, he gave an affirmative "hmm" and said " $m k$ honzen". This is a traditional type of dancing and clapping hands, characteristic of the Nazarene church. Nomusa affirmed that Mvelo was always at the front when they were dancing, and he laughed and clapped his hands during church.

When asked what she wished she could do that she was unable to do, Amahle said: "I will take my flip-flops, put them on and walk to church. I will also wear my church garments." Amahle was able to express her desire for more independence in dressing and mobility. She wanted to walk to church, which her mom described as a happy, communal walk, hinting at inclusion and acceptance for Amahle. Spirituality was important to Amahle, not only in what she dreamed to achieve, but also the fact that she trusted God to help her walk. During her interview, Amahle started singing "Nkulunkulu uthando Iwakho" meaning "Lord, your love", a song Nompilo said they often sang together at home. While Nompilo continued singing, Amahle asked Shembe (God) to make her walk and stop using crutches or a walking frame. She believed God was able to help her walk. Similarly, Thuli stated: "they encourage me by telling me that God will not give me a load that I will not bear".

\section{Financial difficulties}

Family finances were mentioned as an area of concern. "Mothers have had the father of their child leave them all alone to support the child" (Thabile, parent). Sizwe's father stopped his support after the CP diagnosis. "He doesn't contribute financially anymore" (Buhle, parent).

Parents mentioned that the social grant they received from the government was not enough to pay for their expenses. Being unable to work due to full-time caregiving, made it difficult for families to manage financially.

"If possible, we would like the government to pay us a separate grant as parents of these children so that we are able to help ourselves and our children better" (Nompilo).

"Some of us do not have people who support us financially, which means that you do everything with the child's grant, and you cannot go to look for work because you do not have someone who will look after your child" (Thabile).

Furthermore, there were additional costs associated with having a disability, such as special toiletries, "he uses diapers" (Nelisiwe), and having to access healthcare more often.

"I wait until I get transport to get her to the doctor. Sometimes I do not have money and have to borrow." (Thuli).

Access to services
Access to healthcare remained difficult, especially with the children's mobility challenges and the vast, hilly nature of the terrain where they lived. All these families attended local primary healthcare clinics in their rural areas. Nurses manned the clinics, with therapists and doctors visiting once a month. Nomusa (parent) stated "there has been a lot of improvement with the limited services that there are. It's better than nothing at all”, but Buhle, another parent believed "it won't be enough".

Unfortunately, health professionals did not always explain the children's diagnoses to the families. Thabile did not receive an accurate explanation about Ntombi's condition. "I was told that the child has Down syndrome." Ntombi did not have Down syndrome and was diagnosed with $\mathrm{CP}$ after therapists referred her back to the doctor for re-evaluation. The lack of information to caregivers also caused some unrealistic expectations about their children's functioning: "when she reaches a stage where she is better, she can start with education" (Thabile).

Although health services were limited, the families showed gratitude for the mobile rehabilitation teams. Nomfundo said she was happy with the therapy that Mbali had received.

"I have seen the therapists give her something and now she can hold onto it. One of her legs is straightening as a result of therapy." Zanele shared her sentiments: "The clinic really works. It has helped me a lot."

Transport challenges also had an effect on children's QOL. "We find a lot of difficulty when using public transport" (Nompilo, parent). This was due to the attitudes of others on the taxis, as well as the distances to the taxi stops. More worrying for the parents was the fact that "the ambulance takes a very long time to get where we are" (Nomusa). The parents did not think this would change soon. "We do not receive any assistance, and the way I see it the District does not even know that we exist" (Thabile, parent).

\section{Thinking about the future}

Despite the adversity, caregivers had positive dreams and hopes for their children's futures. "One day [Sizwe] will have his own bathroom, bedroom and a proper education at school" (Buhle, parent). Caregivers also mentioned that having a child with $\mathrm{CP}$ had taught them some lessons. "[It] has helped me with learning to love. I used to love my child but now it has grown" (Thabile). Older caregivers had some fears about the future of their children:

"I am worried that one day I will no longer be around and then no one will look after (Mbali). I'm praying that God will keep me until the other siblings are old enough (to care for Mbali)." (Nomfundo).

\section{DISCUSSION}

This study provided insight into the daily lives of rural children with $\mathrm{CP}$ as well as their caregivers' thoughts about their QOL. Various authors have described the different domains of QOLI9-2I, but no consensus exists on what should constitute the different domains ${ }^{19}$, or whether they are valid or relevant for children with $\mathrm{CP}$, or how these domains manifest in the rural context. The findings of this study highlighted domains of QOL that were important to the participants, as set out in the themes. The participants' responses also offered more information regarding their experiences, which can be seen as the indicators that are relevant to this context for each domain of QOL. This is helpful to therapists working in the rural context, as indicators can be used to formulate specific, measurable goals for treatment and intervention.

From the data, it was clear how the children's physical abilities impacted on their inclusion, participation and QOL. Children's inclusion and interaction with others improved once they started sitting 
independently. Gross motor abilities also allowed Mvelo to attend formal schooling, although it was only a crèche. These findings are in line with a South African study of teens with CP and their participation in physical activities. Physical limitations such as range of motion and physical pain were identified as barriers to participation for the teenagers ${ }^{22}$.

Mvelo and Amahle were included in household activities as they were able to use their hands in a more coordinated manner than the other children. Hand function has been mentioned as having a direct impact on QOL for children with $\mathrm{CP}$, regardless of where they live $^{22,23}$. Polish researchers highlighted the importance of improving hand function for more activity participation and higher $\mathrm{QOL}^{23}$. This study's findings are therefore in line with international QOL research, and rural occupational therapists ought to prioritise the improvement of children with CP's hand function, as this is one of the main ways in which children explore the world around them and participate in activities and play.

The parents' worries about communication, specifically with regards to pain had also been documented by other studies. An American study ${ }^{24}$ mentioned that the aetiologies of pain were often difficult to determine if children had limited cognitive and communication abilities. They further mentioned that "pain had an impact on the child's quality of life and participation"24:308, which corroborated with the parent-proxies' responses. The link between pain and poorer QOL has been shown in recent studies of children with $\mathrm{CP}^{25,26}$

Participation in specific activities was important to the children and families to experience a high QOL. The availability of appropriate schooling, engagement in community activities, chores at home and playing with others were all mentioned by both the children and the parent-proxies as being important. These are similar to the results from an Australian study of the $\mathrm{QOL}$ of children with $\mathrm{CP}^{17}$.

The difference from the Australian study would be the greater availability of services such as schools for children with disabilities, as it was a developed country. While both the participants in this study and the Australian participants considered schooling important, the children of this study did not have the option of going to a school in their communities, highlighting the importance of a comprehensive understanding of the settings these children lived in, and the effect of systemic issues on the QOL of the rural South African children. It also demonstrated the impact of the failure to implement existing inclusive education policies in South Africa.

Participation in occupation is an integral part of QOL, and of specific significance to occupational therapists. According to the World Federation of Occupational Therapists (WFOT) the primary goal of occupational therapy is "to enable people to participate in the activities of everyday life"27:I. The children's participation in activities is where occupationally therapists have the biggest influence in improving the QOL of children with $\mathrm{CP}$ in rural areas. The findings mentioned specific activities that are important to the children and their families and provides the rural therapist with the indicators for QOL that need to be addressed in interventions.

The findings revealed the limited variety of activities rural children with CP were able to participate in, as well as the low frequency of participation. This is in keeping with a recent comparative Serbian study that found that children with CP "participated in fewer activities at home and in the community, less frequently and had lower levels of involvement" compared to children with typical development ${ }^{28: 78}$.

As known from previous studies, the degree of participation in activities of children with disabilities is at least in part "a product of their environment"7:292. It was therefore imperative to fully understand the children's limitations within their environment and to challenge the disabling environment. The data highlighted the fact that caregivers were major role players in their children's QOL. It is known that the wellbeing of caregivers were inextricably linked to the wellbeing of those they care for ${ }^{4,29}$, but this study also highlighted the impact of caregivers' beliefs and abilities on children's QOL. Children with similar physical abilities were exposed to different activities because of the attitude or beliefs of the parent, as seen with Nkululeko and Zanele.

It was not only the caregivers' attitude towards CP that affected the children's QOL. Some children were limited in their community interaction due to their caregivers' age and inability to carry them to events. Children with older caregivers had limited participation whereas the physical demands of carrying a child with CP was something a younger caregiver could cope with, leading to more interaction with others and higher activity participation. This is in contrast to the Polish study where it was found that the age of the caregiver and child had a limited impact on a child's $\mathrm{QOL}^{23}$. This could be linked to the improved services available to caregivers in the Polish communities. Caregivers were also the ones who would either advocate for services for their children, or just accept the limited services that were available, as some caregivers stated these services were better than nothing.

Community members' attitudes were reported as both limiting and contributing to the children's QOL. Misinformation and stigma about disabilities was the biggest problem. This correlated with a South African study comparing the environmental barriers of rural and urban people with disabilities. This study showed that beliefs in rural settings tend to be more traditional and superstitions were common, reinforcing the negative attitudes experienced by people with disabilities ${ }^{30}$.

Attending church gave participants and their caregivers an outlet for their need for spiritual expression. Turning to religion occurs frequently when people encounter traumatic events in their lives, offering refuge and solace during stressful times. This religious coping strategy can take an active form where people pray or perform religious rituals, or a passive form where they leave their burdens with God $^{31}$. Moreover, it instilled hope that God would answer their prayers and minimize the burdens of the caregivers. Acceptance of their children's illnesses was also facilitated, and this enabled coping, which gave the parents' lives meaning and purpose. Spiritual coping occurs in all cultures with parents of children with developmental disabilities, including Jewish ${ }^{32}$ and Muslim societies ${ }^{33}$.

The lack of services was evident in the environment these children lived in. It was striking that many of the parents were misinformed about their children's diagnoses, or the chronic nature of the condition. Lack of comprehensive explanations and adequate health services meant false beliefs and stigma around witchcraft continued to be perpetuated.

All the children in this study attended regular therapy at their local primary healthcare clinics, yet many of them still did not have a wheelchair to improve their access to services. Children became too heavy to carry, leading to a life lived only in and around the home. The vast, hilly landscape meant the closest points of access were still many kilometres away from their homes. They often had to cross rivers and walk steep hills, making it difficult to navigate to services, especially if the child had to be carried. By motivating for and issuing wheelchairs to children with $C P$, occupational therapists can have a concrete impact on the QOL of these children. 
According to Hagerty et al., subjective indicators of wellbeing or QOL was essential, yet not sufficient to capture the totality of life experience ${ }^{34}$. Similarly, objective QOL conditions, which were aspects that could be measured independently may have very little to do with a person's perception of their wellbeing ${ }^{34}$. This study captured the perceptions of wellbeing of children with CP and their families. The parent-proxies provided information that is important for the children's QOL, which the children themselves may not be aware of, whether due to age or intellectual abilities. Combined, these findings provide occupational therapists and other health professionals with a detailed understanding of the $\mathrm{QOL}$ of children with $\mathrm{CP}$ in rural areas.

\section{RECOMMENDATIONS}

The findings confirmed that QOL was multi-faceted. In a complex rural setting, this became an even greater phenomenon to understand. Some of the factors influencing QOL fell within the client factors, some on the societal level, and others on a wider systemic level. While some factors like providing a wheelchair and working on improving hand function were relatively easy to achieve, factors that fell within the societal and systemic spheres might take longer and require more dedicated input to change $\mathrm{e}^{35}$. However, as physical wellbeing is the most severely impacted domain of $\mathrm{QOL}$ in children with $\mathrm{CP}^{36}$, some of the easier interventions, like providing off-road wheelchairs, could provide the greatest QOL improvements.

Caregivers play a pivotal role in the $\mathrm{QOL}$ of children with $\mathrm{CP}$ in rural areas. Health education and parent support programmes, including respite care should be enhanced. Improved training of health professionals will decrease incorrect diagnoses and misinformation being shared with parents. Empowered parents are also more likely to advocate for better services for their children. Awareness campaigns in the communities should be used to reduce stigma and promote understanding of $\mathrm{CP}$, leading to better inclusion and acceptance for rural children with CP.

Systemic changes such as an increased number of inclusive schools in rural areas, improved healthcare and more regular therapy were also needed to improve the QOL of children. Lobbying for better schooling for these children should include advocating for the implementation of existing policies such as the Department of Education's White Paper 6 to improve the rural children with disabilities' $\mathrm{QOL}^{37}$.

\section{LIMITATIONS OF THE STUDY}

The children with CP that met the inclusion criteria had complex presentations of CP. It was difficult to identify child participants who could communicate with unfamiliar people. The two child participants both had speech difficulties, but the researcher considered it important to give them the opportunity to voice their opinions. This study therefore only included two children who could communicate with the researcher, and caregiver-proxies were used for the rest. Using the hospitals for identifying possible participants meant that only children with $\mathrm{CP}$ that attended therapy were included in this study. Children with less supportneeds, who did not attend regular therapy, were not included in this study, making it difficult to identify children in this age band who could give a subjective account of their QOL. Furthermore, due to the landscape, children with $\mathrm{CP}$ were not often known to the services, unless they accessed services. A child who is housebound might have a different QOL to the children in this study and necessitates more research in this area.

\section{CONCLUSION}

Quality of Life (QOL) is a complex construct that has not been extensively researched in rural areas with high levels of poverty, such as the Umzinyathi district. This study provided valuable insight into the aspects that affected the QOL of children with $C P$ in the rural South African context. Limited resources and finances would make it difficult to implement change on a large scale but understanding the environment and the identified aspects impacting QOL would allow occupational therapists to use $\mathrm{QOL}$ as an outcome measure for treatment.

Although health and education services were lacking in rural areas, it was important to note that all the parents were satisfied with the service and treatment they received from the rehabilitation teams at their local clinics. This provided evidence that despite hardships in rural areas that impacted on QOL, therapists had the opportunity to positively impact the QOL of rural children with $C P$.

The occupational therapists' role in improving the QOL of rural children with CP would be to provide support and information to caregivers on $\mathrm{CP}$, as well as offering practical ideas for inclusion and stimulation. It is important that caregivers feel empowered to advocate for their children in these communities where they might experience animosity and isolation on a regular basis. Furthermore, it is imperative that occupational therapists listen to children with $\mathrm{CP}$ and understand what is important to them. As health professionals, occupational therapists are also in a strategic position to advocate for expansion of inclusive health and education services to rural areas, thereby positively impacting the $\mathrm{QOL}$ of children with $\mathrm{CP}$.

\section{ACKNOWLEDGEMENTS}

The authors would like to acknowledge the following people and institutions: The children and caregivers who participated in this study, Princess Dlamini and Nokwanda Mshengu for translations, and Staff of the Umzinyathi District Department of Health for their support.

\section{AUTHOR CONTRIBUTIONS}

Annika Savage was the primary researcher as a Master of Occupational Therapy candidate and was involved in the conceptualisation of the study, data collection, - analysis and drafting of the manuscript. Gina Rencken and Thavanesi Gurayah served as supervisors of the study and provided input into research design, concept development, operationalisation of the study, writing assistance and editing of the article.

\section{CONFLICTS OF INTEREST DECLARATIONS AND FUNDING}

There are no financial or non-financial conflicts of interest to declare. The Ruth Watson Research Grant (administered by OTASA's research committee) contributed financially to this research study.

\section{DATA AVAILABILITY STATEMENT}

Requests to access the data of this study can be emailed to the main author.

\section{REFERENCES}

I. Rosenbaum P, Livingstone M, Palisano R, Galuppi B, Russell D. Quality of life and health-related quality of life of adolescents with cerebral palsy. Dev Med Child Neurol. 2007;49:516-52I. https://doi.org/I0.1 I I I/j. I469-8749.2007.005 I6.x

2. McLaren $P$. How can we strengthen primary health care for children with cerebral palsy in rural areas of South Africa? Hands-on Learn 
Exp Inclusive, enabling communities (Learning $\mathrm{Br} 55$ ). Published online 2014.

3. Quinn T, Gordon C. The Effects of Cerebral Palsy on Early Attachment : Perceptions of Rural South African Mothers. J Hum Ecol. 2011;36(3):191-197.

https://doi.org/I0.1080/09709274.201।.II906435

4. Rosenbaum P. Family and quality of life : key elements in intervention in children with cerebral palsy. Published online 201 I:68-70. https://doi.org//0.1 I I I/j. I469-8749.201 I.04068.x

5. Power R, Akhter R, Muhit M, et al. A quality of life questionnaire for adolescents with cerebral palsy: psychometric properties of the Bengali CPQoL-teens. Health Qual Life Outcomes. 2019; I (I). https://doi.org/I0.II86/s I2955-019-1206-x

6. Hammell KW. Quality of life, participation and occupational rights: A capabilities perspective. Aust Occup Ther J. 2015;62(2):78-85. https://doi.org/10.1111/1440-1630.12183

7. Hammal D, Jarvis SN, Colver A. Participation of children with cerebral palsy is influenced by where they live. Dev Med Child Neurol. 2004;46(5):292-298.

https://doi.org/I0.1 I I I/j. I 469-8749.2004.tb00488.x

8. Burton A. Fighting cerebral palsy in Africa. Lancet Neurol. 20I5; I4(9):876-877.

https://doi.org/I0.1016/SI474-4422(15)00189-I

9. Bearden D, Monokwane B, Kolson D, Bisson G. Risk Factors for Cerebral Palsy in Botswana (P4.297). Neurology. 2014;82(10 Supplement). https://doi.org/10.1016/j.pediatrneurol.2017.07.014

10. Dodge R, Daly A, Huyton J, Sanders L. The challenge of defining wellbeing. Int J Wellbeing. 20I 2;2(3):222-235.

https://doi.org// 0.5502/ijw.v2i3.4

II. Davis E, Shelly A, Waters E, Davern M. Measuring the quality of life of children with cerebral palsy: comparing the conceptual differences and psychometric properties of three instruments. Dev Med Child Neurol. 2010;52(2): I 74- 180.

https://doi.org//0.1 I I I/j. I469-8749.2009.03382.x

12. Liddle J, McKenna K. Quality of life: An overview of issues for use in occupational therapy outcome measurement. Aust Occup Ther J. 2000;47(2):77-85.

https://doi.org//0.1046/j. I440-1630.2000.00217.x

13. Hammell KW. Spinal Cord Injury; Quality of Life; Occupational Therapy: Is There a Connection? Br J Occup Ther. 1995;58(4): I5II57. https://doi.org/ I0. I 177/030802269505800403

14. Denzin NK, Lincoln YS. Introduction The Discipline and Practice of Qualitative Research. Handbook of Qualitative Research. Published online 2006: I-20.

15. Health-e. Kwazulu Natal Umzinyathi District Profile. Published online 20I3. http://www.health-e.org.za/wp-content/uploads/2013/06/Umzinyathi-District-Profile.pdf

16. KZN Department of Health. Umzinyathi District Health Plan. Published online 2015.

http://www.kznhealth.gov.za/Strategic/DHP/2015-16/Umzinyathi.pdf

17. Waters E, Maher E, Salmon L, Reddihough D, Boyd R. Development of a condition-specific measure of quality of life for children with cerebral palsy: empirical thematic data reported by parents and children. Child Care Health Dev. 2005;3 I (2): I 27- I 35.

https://doi.org//0.1 I II/j. |365-2214.2004.00476.x

18. Braun V, Clarke V. Chapter 4: Thematic Analysis. APA Handb Res Methods Psychol. 2012;2:57-71.

https://doi.org/10.1037/13620-004

19. Petry K, Maes B, Vlaskamp C. Domains of quality of life of people with profound multiple disabilities: The perspective of parents and direct support staff. J Appl Res Intellect Disabil. 2005; I ( (I):35-46.
https://doi.org/I0.1 I I I/j. I468-3 | 48.2004.00209.x

20. Deepthi N, Krishnamurthy A. Mental Health and Quality of Life of Caregivers of Individuals with Cerebral Palsy in a Community Based Rehabilitation Programme in Rural Karnataka. Disabil , CBR Incl Dev. 201 I;22(3):29-38.

https://doi.org//0.5463/DCID.v22i3.56

21. Nagabushana D, S. PK, Agadi JB. Impact of epilepsy and antiepileptic drugs on health and quality of life in Indian children. Epilepsy Behav. 2019;93:43-48. https://doi.org/10.1016/j.yebeh.2019.01.021

22. Conchar L, Bantjes J, Swartz L, Derman W. Barriers and facilitators to participation in physical activity: The experiences of a group of South African adolescents with cerebral palsy. J Health Psychol. Published online 20 I4. https://doi.org/I0. I I77/I 359I053 I 4523305

23. Kołtuniuk A, Rozensztrauch A, Budzińska P, Rosińczuk J. The Quality of Life of Polish Children with Cerebral Palsy and the Impact of the Disease on the Family Functioning. J Pediatr Nurs. 2019;47:e75-e82. https://doi.org/10.1016/j.pedn.2019.05.01 I

24. Houlihan CM, O'Donnell M, Conaway M, Stevenson RD. Bodily pain and health-related quality of life in children with cerebral palsy. Dev Med Child Neurol. 2004;46(5):305-310. https://doi.org/10.1 I I I/j. 1469-8749.2004.tb00490.x

25. Dickinson HO, Parkinson KN, Ravens-Sieberer U, et al. Self-reported quality of life of 8- 12-year-old children with cerebral palsy: a cross-sectional European study. Lancet. 2007;369(9580):2I 7 I 2178. https://doi.org/10.1016/S0140-6736(07)61013-7

26. Colver A. Measuring quality of life in studies of disabled children. Paediatr Child Health (Oxford). 2008; 18(9):423-426. https://doi.org/10.1016/j.paed.2008.05.01 I

27. World Federation of Occupational Therapists. Statement on occupational therapy. August. Published online 201 I: I. https://wfot.org/resources/statement-on-occupational-therapy

28. Milićević M, Nedović G. Comparative study of home and community participation among children with and without cerebral palsy. Res Dev Disabil. 2018;80(July 2017):74-83.

https://doi.org/10.1016/j.ridd.2018.06.010

29. Gurayah T, Govender P, Naidoo D, Fewster DF, Lingah T. Faces of caregiving in a South African context. In: Sakellariou D, Pollard, N. Occupational Therapies Without Borders: Integrating Justice with Practice. 2nd ed. Elsevier; 2017:372-380. ISBN 9780702059209.

30. Maart S, Eide AH, Jelsma J, Loeb ME, Ka'Toni M. Environmental barriers experienced by urban and rural disabled people in South Africa. Disabil Soc. 2007;22(4):357-369. https://doi.org/10.1080/09687590701337678

31. Hatun O, Yavuz Birben F, İnce Z, Yeni G. The Ticket to Heaven: A Spiritual Resource for Coping with Disability. Spirit Psychol Couns. 2016; I. https://doi.org/I0.12738/spc.2016.2.0013

32. Pandya SP. Spirituality and Parents of Children With Disability: Views of Practitioners. J Disabil $\backslash \&$ Relig. 20I7;2I(I):64-83. https://doi.org/10.1080/23312521.2016.1270178

33. Ozpak AM, Tekin O, Arslan I, et al. Investigation of Healthy Living Behaviors of Parents with Disabled Children. KONURALP TIP Derg. 20I7;9(3): I88-195. http://doi.org/10.1852 I/ktd.320I34

34. Hagerty MR, Cummins R, Ferriss AL, et al. Quality of life indexes for national policy: Review and agenda for research. Bull Méthodologie Sociol. 200I;7I(I):58-78. https://doi.org/10.1177/075910630107100104

35. Guan S, Deng G. Whole-community intervention for left-behind children in rural China. Child Youth Serv Rev. 2019;10I(March): I-II. https://doi.org/10.1016/j.childyouth.2019.03.033

36. Power R, King C, Muhit M, et al. Health-related quality of life of children and adolescents with cerebral palsy in low- and middle- 
income countries: a systematic review. Dev Med Child Neurol. 2018;60(5):469-479. https://doi.org//0. I I I /dmcn. I 368 I

37. Nel I. Education for children with disabilities in South Africa. Published 2018. Accessed January 28, 2020.

https://www.action4.org.za/education-for-children-with-disabilities-in-sa/

\section{Corresponding Author}

*Annika Savage

Email: savage.annika@gmail.com 